\title{
TUNING OF MAGNETIC PROPERTIES AND DOMAIN STRUCTURE IN FeCo- AND FeSi-BASED SOFT MAGNETIC ALLOYS BY THERMAL PROCESSING UNDER MAGNETIC FIELD
}

\author{
Jozef MARCIN*, Marek CAPIK*, Jozef KOVÁČ ${ }^{*}$, Peter ŠVEC ${ }^{* *}$, Ivan PETRYSHYNETS ${ }^{* * *}$, \\ František KOVÁČC $^{* * *}$, Ivan ŠKORVÁNEK ${ }^{*}$ \\ *Institute of Experimental Physics, Slovak Academy of Sciences, Watsonova 47, 04001 Košice, Slovak Republic \\ ${ }^{* * *}$ Institute of Physics, Slovak Academy of Sciences, Dúbravská cesta 9, 84228 Bratislava, Slovak Republic \\ **** Institute of Material Research, Slovak Academy of Sciences, Watsonova 47, 04001 Košice, Slovak Republic, \\ e-mail: skorvi@saske.sk
}

\begin{abstract}
Thermal processing of materials in external magnetic field is employed in order to produce a controllable uniaxial anisotropy and to tailor a domain structure in the series of soft magnetic Fe-based alloys. Of particular interest for this work are the advanced silicon steels with low coercivity as well as the soft magnetic FeCo based amorphous/nanocrystalline alloys. The beneficial effects of a heat treatment under magnetic field are discussed in terms of the improved magnetic softness and the possibility to tune the application-oriented properties of these alloys.
\end{abstract}

Keywords: soft magnetic alloys, FeSi electrical steels, thermal processing, magnetic annealing, domain structure

\section{INTRODUCTION}

The continuing interest in development of new soft magnetic alloys is driven by industrial need to enhance the performance of electrical power generation/distribution systems as well as magnetic sensors and energy conversion devices. In order to achieve the requested properties, the soft magnetic alloys often require specific annealing conditions. One possible processing technique, which can be employed for tuning their magnetic characteristics for specific applications is the thermal treatment under the presence of external magnetic field, called also "magnetic annealing”.

Magnetic annealing often leads to appearance of induced magnetic anisotropy in the heat treated soft magnetic alloys. Here, the other anisotropy contributions are usually small, and hence, the induced anisotropy may dominate [1]. In many soft magnetic materials including various crystalline and amorphous alloys, the phenomenon of field annealing induced anisotropy is often explained in terms of magnetic atoms pair ordering mechanism. According to the model for binary alloys proposed independently by Néel [2] and Taniguchi [3], the directional diffusion takes place with a preferred direction of magnetic atom pairs imposed by the direction of magnetization during the annealing and/or subsequent cooling. The compositional dependence of induced anisotropy constant, $K_{u}$, for binary $A_{x} B_{1-x}$ alloy is predicted to go as $\mathrm{x}^{2}(1-\mathrm{x})^{2}$, therefore, the strongest effects are expected for the compositions with equal population of A and B constituent atoms. Such behaviour has been indeed observed for many systems with two kinds of magnetic atoms e.g. for Fe-Ni-based amorphous alloys [4]. and Fe-Co-based nanocrystalline alloys [5].

Although, most of the research on magnetic annealing has been devoted to the various binary and ternary alloys of $\mathrm{Fe}, \mathrm{Co}$, and $\mathrm{Ni}$, the effects of field annealing were found to be present also in the alloy systems with only one kind of magnetic atoms such as silicon steel sheets [6] and more recently developed Fe-Cu-Nb-B-Si [7] and Co(Zr,Nb)-B-Cu nanocrystalline alloys [8,9]. Here, an important role in development of the field-annealing induced anisotropy seems to be played by metalloid atoms and other mobile minority atoms/defects species.

In this work, a controllable field-induced magnetic anisotropy is produced in series of amorphous, nanocrystalline and crystalline alloys with different composition.

Our composition choice was motivated as follows:

i) $\quad$ Fe-Co-Nb-B-based amorphous alloy represents a system with the Curie temperature considerably exceeding its (nano)crystallization temperature.

ii) non-oriented silicon steel sheets taken from industrial line represent a system with only one kind of magnetic atoms and non-negligible magnetocrystalline anisotropy.

We report on the beneficial effects of both longitudinal and transverse magnetic field applied during the heat treatment process on the application-oriented magnetic characteristics of these soft ferromagnets.

\section{Fe-Co-Nb-B AMORPHOUS AND NANOCRYSTALLINE ALLOYS}

Amorphous $\left(\mathrm{Fe}_{0.5} \mathrm{Co}_{0.5}\right)_{81} \mathrm{Nb}_{7} \mathrm{~B}_{12}$ ribbons $6 \mathrm{~mm}$ wide and $\sim 20 \mu \mathrm{m}$ thick were produced by planar flow casting. Pieces of these ribbons (60 mm long) were annealed under a high vacuum for 1 hour at temperatures $673 \mathrm{~K}$ and $773 \mathrm{~K}$ in order to prepare a set of relaxed amorphous and nanocrystalline samples characterized by different microstructure.

The changes of microstructure upon annealing were investigated by transmission electron microscopy (TEM), and X-ray diffraction (XRD). TEM and electron diffraction observations were performed using JEM1200 EX microscope. 


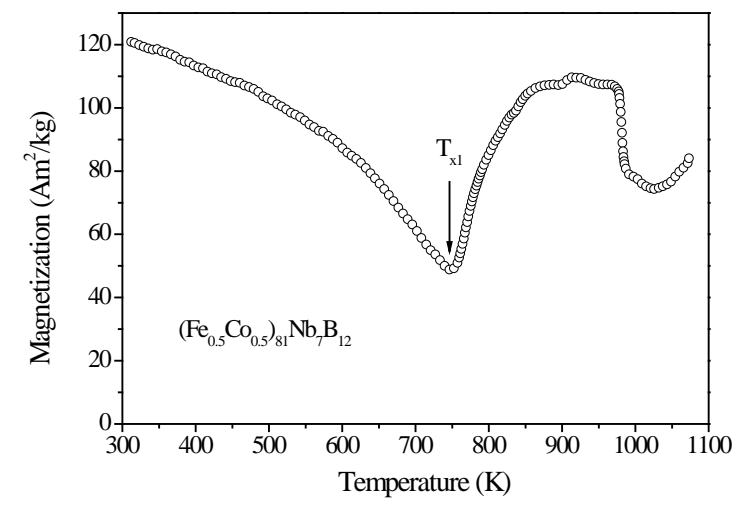

Fig. 1 Thermomagnetic plot of $\left(\mathrm{Fe}_{0.5} \mathrm{Co}_{0.5}\right)_{81} \mathrm{Nb}_{7} \mathrm{~B}_{12}$ sample

The samples with preferred direction of induced anisotropy were prepared by isothermal annealing in the presence of transverse (TF) or longitudinal (LF) magnetic field. In the case of TF-annealed samples, the furnace was placed inside the commercial permanent magnet system (Magnetic Solutions LTD) producing a magnetic field of $640 \mathrm{kA} / \mathrm{m}$. In the LF-annealed samples, the solenoidal coil that provided a magnetic field of $20 \mathrm{kA} / \mathrm{m}$ was used. After annealing, the specimens were slowly field-cooled down to room temperature. The reference samples were annealed and cooled in a zero magnetic field (ZF).

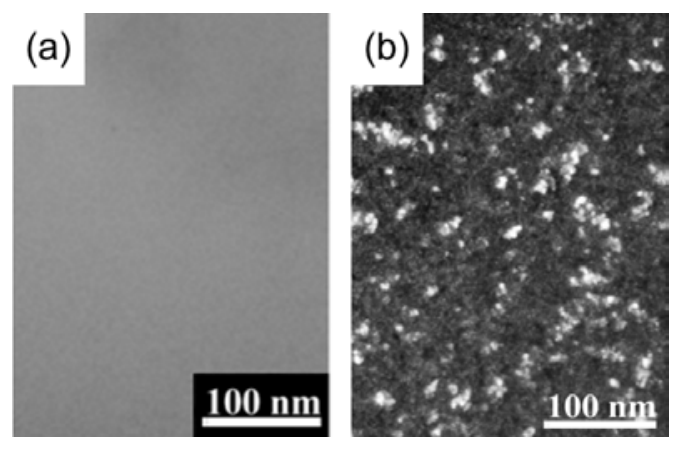

Fig. 2 TEM micrographs of $\left(\mathrm{Fe}_{0.5} \mathrm{Co}_{0.5}\right)_{81} \mathrm{Nb}_{7} \mathrm{~B}_{12}$ samples annealed for 1 hour at $673 \mathrm{~K}$ (a) and $773 \mathrm{~K}$ (b)

The magnetization measurements were performed by vibrating sample magnetometer (VSM) over the temperature range from 300 to $1100 \mathrm{~K}$, in a field $240 \mathrm{kA} / \mathrm{m}$ and a heating rate $10 \mathrm{~K} / \mathrm{min}$. The effects of the magnetic annealing on the hysteresis loops and on the domain structure were investigated by Forster type B-H loop tracer and magneto-optical Kerr microscope, respectively.

Fig. 1 shows the temperature dependence of magnetization for the as-quenched sample. The first fall of magnetization after increase of the measuring temperature corresponds to the ferro-paramagnetic transition of the amorphous alloy, Tc(am). An abrupt increase of magnetization at temperatures above $700 \mathrm{~K}$ is related to the primary crystallization process, where the ferromagnetic Fe-Co grains with Tc higher than the measuring temperature are formed. It can be seen that the Curie temperature exceeds the corresponding crystallization temperature, which is desirable for high temperature applications [10].
Fig. 2 shows the transmission electron micrographs of the samples heat treated for 1 hour at $673 \mathrm{~K}$ and $773 \mathrm{~K}$, respectively. The sample annealed for 1 hour at $673 \mathrm{~K}$ exhibit a presence of the amorphous phase only. On the other hand, ultrafine grains with typical grain dimensions ranging from 4-10 nm were observed after nanocrystallization of sample at $773 \mathrm{~K}$.

Fig. 3 and 4 show domain structure patterns for the samples of $\left(\mathrm{Fe}_{0.5} \mathrm{Co}_{0.5}\right)_{81} \mathrm{Nb}_{7} \mathrm{~B}_{12}$ annealed at $773 \mathrm{~K}$ in zeroand transverse field, respectively. The domain structure of the zero-field annealed sample (Fig. 3) is rather complex and exhibit a coexistence of wide domains as well as the regions with narrow mazy closure domains. On the other hand, the domain structure of field annealed sample is simple (Fig. 4), Here, the wide transverse slab domains, will favour the magnetization rotations to be dominant magnetization processes.

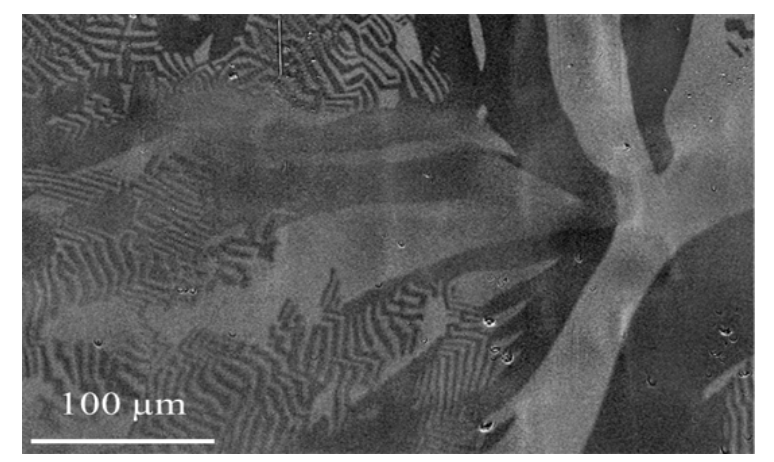

Fig. 3 Magnetic domain structure of $\left(\mathrm{Fe}_{0.5} \mathrm{Co}_{0.5}\right)_{81} \mathrm{Nb}_{7} \mathrm{~B} 12$ after annealing at $773 \mathrm{~K}$ for 1 hour at zero-field conditions

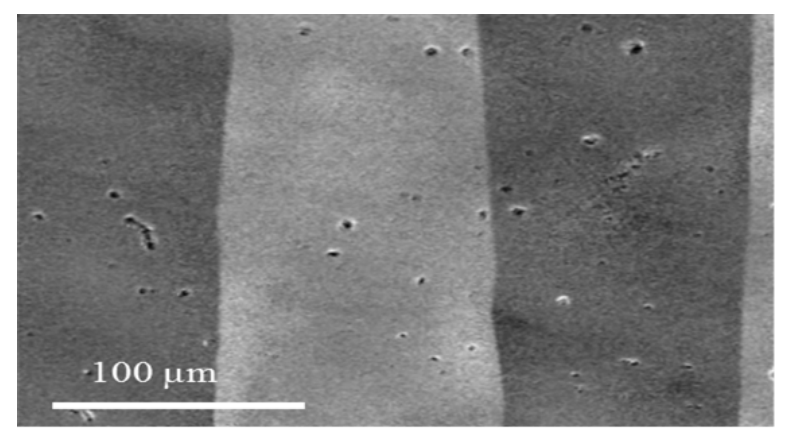

Fig. 4 Magnetic domain structure of $\left(\mathrm{Fe}_{0.5} \mathrm{Co}_{0.5}\right)_{81} \mathrm{Nb}_{7} \mathrm{~B}_{12}$ after annealing at $773 \mathrm{~K}$ for 1 hour in transverse magnetic field of $640 \mathrm{kA} / \mathrm{m}$

A main attention of this work has been devoted to the study of the effects of annealing under presence of external magnetic field in order to induce controllable uniaxial anisotropy in the samples.

The effect of field annealing on the hysteresis loops of $\left(\mathrm{Fe}_{0.5} \mathrm{Co}_{0.5}\right)_{81} \mathrm{Nb}_{7} \mathrm{~B}_{12}$ alloy is demonstrated in Fig. 5. The shape of the hysteresis loop is governed by a balance between domain wall displacement and magnetic moment rotation processes. According to the direction of the induced anisotropy, the magnetization curves with large or small squareness ratio could be obtained after annealing in longitudinal or transverse magnetic field, respectively. 

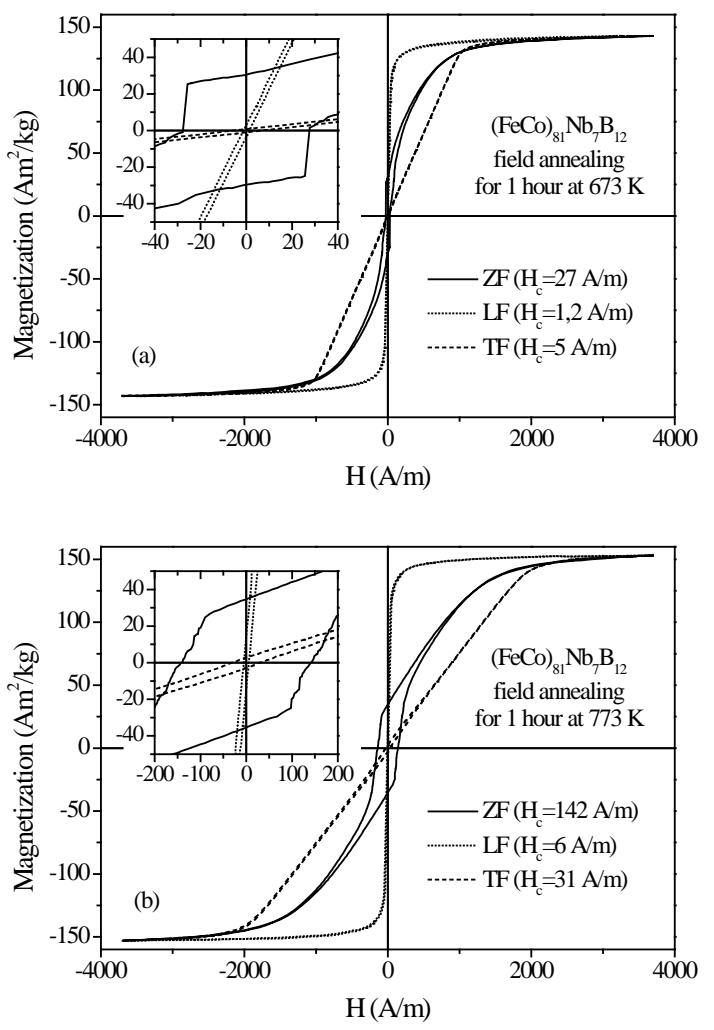

Fig. 5 Hysteresis loops for $\left(\mathrm{Fe}_{0.5} \mathrm{Co}_{0.5}\right)_{81} \mathrm{Nb}_{7} \mathrm{~B}_{12}$ after different field annealing for 1 hour at indicated temperature

The rotation processes tend to dominate after annealing in the transverse magnetic field, and consequently, the sheared loops with relatively good field linearity are achieved. Such characteristics are of particular interest for high frequency transformers and magnetic sensors. A heat treatment under the presence of longitudinal magnetic field results in squared hysteresis loops that are characterized by a significant reduction of the coercivity. The coercive field values in the range of $2-6 \mathrm{~A} / \mathrm{m}$ are superior to those previously reported for the FeCo-based nanocrystalline alloys [11-15]. We can see from Fig. 5 that the annealing without the presence of external magnetic field leads to an appreciable increase of the coercivity and the corresponding hysteresis loops exhibit a presence of steps due to the depinnig of domain walls from the positions stabilized during the heat treatment. The domain wall stabilization effects are particularly pronounced in the case of thermally relaxed $\left(\mathrm{Fe}_{0.5} \mathrm{Co}_{0.5}\right)_{81} \mathrm{Nb}_{7} \mathrm{~B}_{12}$ amorphous sample as can be seen from the enlarged central part of the corresponding hysteresis loop depicted in Fig. 5 (a).

\section{FeSi STEEL SHEETS}

The effects of annealing under presence of external magnetic field were studied also in the vacuum degassed NO silicon steel sheets with the following chemical composition: $\mathrm{C}=0.008, \mathrm{Mn}=0.22, \mathrm{Si}=2.9, \mathrm{Cu}=0.048$, $\mathrm{P}=0.006, \mathrm{~S}=0.008, \mathrm{Al}=0.05 \mathrm{~N}=0.02, \mathrm{Ti}=0.002 \quad$ wt. $\%$. Strips with thickness of $0.5 \mathrm{~mm}$ were taken from an industrial line after cold rolling with $80 \%$ reduction. The cold rolled specimens were subjected to laboratory recrystallization annealing at $1073 \mathrm{~K}$ for $10 \mathrm{~min}$ in dry hydrogen atmosphere. The steel laminations were subsequently subjected to additional laboratory cold rolling with $4 \%$ reduction. Before the final heat treatment the specimens were cut into strips of $100 \mathrm{~mm} \times 9 \mathrm{~mm}$ with the longest side parallel to the rolling direction.
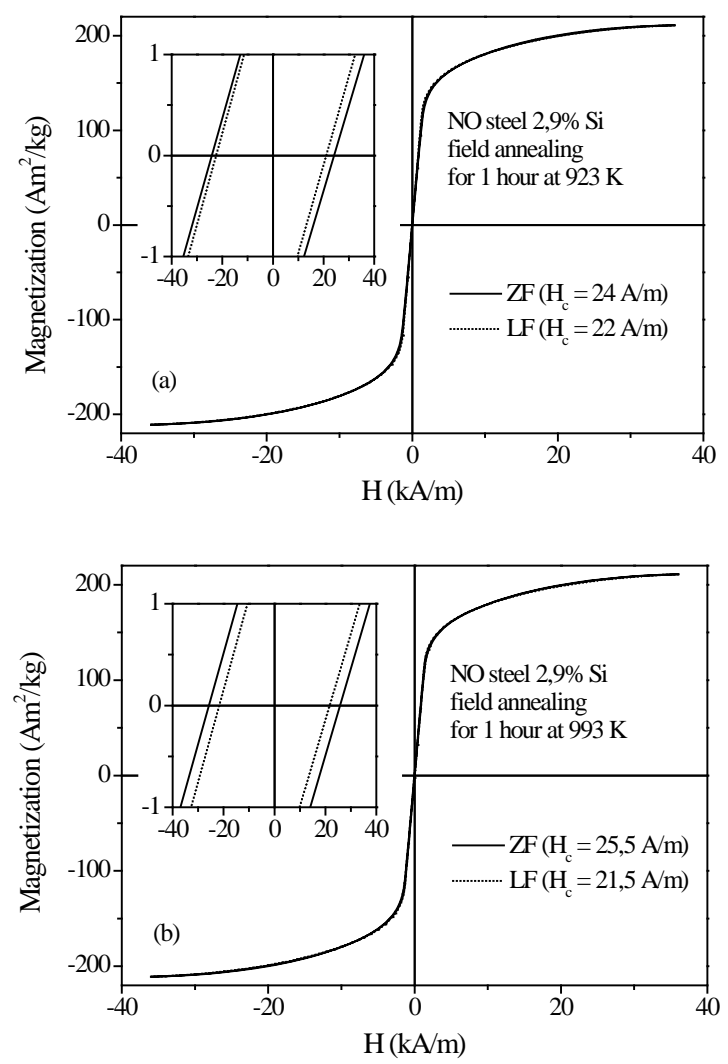

Fig. 6 Hysteresis loops for NO FeSi samples after different field annealing for 1 hour at indicated temperature

Finally, the rolled materials were annealed in pure hydrogen $\mathrm{H}_{2}$ atmosphere upon dynamical heat treatment conditions. The annealing temperature applied to the experimental steel was $1223 \mathrm{~K}$ with holding time $180 \mathrm{sec}$. The basic idea behind this thermo-mechanical treatment was to promote the development of a coarse grained microstructure with pronounced intensity of cube and Goss texture components achieved during a final annealing [16,17]. Such microstructure leads to a significant decrease of the coercivity measured in DC magnetic field. Indeed, the low $\mathrm{H}_{\mathrm{c}}$ values of $\sim 23.5 \mathrm{~A} / \mathrm{m}$ were obtained after the final heat treatment of our $\mathrm{NO}$ silicon steels strips, which were taken as the starting material for subsequent magnetic annealing experiments. The field annealing (LF) was performed in the vacuum furnace inserted in the water cooled solenoidal coil that provided a magnetic field of $40 \mathrm{kA} / \mathrm{m}$ directed along the longest axis of the steel strip specimens. After annealing, the specimens were field-cooled down to room temperature with the cooling rate of $200 \mathrm{~K} / \mathrm{hour}$. The reference samples were annealed and cooled in a zero magnetic field (ZF). Fig. 6 shows the effect of magnetic field annealing on the coercivity of investigated nonoriented electrical steel sheets. The two annealing temperatures were selected below the Curie temperature of specimens containing 2.9 wt.\% Si. In both cases, the coercivities of LF-annealed samples slightly decrease as compared to the ZF-annealed samples, which indicates a 
beneficial effect of the field annealing. The improvement of the magnetic softness in the field annealed $\mathrm{Fe}(\mathrm{Si})$ solid solutions is connected to the directional ordering of Si atoms in the Fe lattice [6]. However, the contribution of induced anisotropy in NO silicon steels is rather small as it is superimposed by their non-negligible random magnetocrystalline anisotropy.

\section{CONCLUSIONS}

A special attention of this work was devoted to the study of the effects of the magnetic annealing in order to control a domain structure and to produce a controllable uniaxial anisotropy in the rapidly quenched FeCoamorphous and nanocrystalline alloys. The specimens annealed without the presence of external magnetic field show an appreciable increase of the coercivity and some hysteresis loops exhibit a presence of large steps due to a depinnig of domain walls from the positions stabilized during annealing. A heat treatment under the application of longitudinal magnetic field results in squared hysteresis loops characterized by very low coercive field values. Sheared loops with tunable slope and good field linearity can be obtained after annealing in transverse magnetic field. The magnetic field annealing effects were investigated also in the series of non-oriented electrical steel sheets containing about 2.9 wt.\% Si. Here, the observed improvement of soft magnetic properties due to heat treatment in static magnetic field is less significant mainly because of the higher magnetocrystalline anisotropy.

\section{ACKNOWLEDGMENTS}

This work was performed within the frame of the project "New materials and technologies for energetics" ITMS: 26220220061, which is supported by the Operational Program "Research and Development" financed through European Regional Development Fund. The partial support of VEGA 2/0209/10 is acknowledged.

\section{REFERENCES}

[1] O`HANDLEY, R. C.: Modern Magnetic Materials : Principles and Applications, John Wiley \& Sons, Inc., New York, 1999.

[2] NÉEL, L.: J. Phys. Radium 15 (1954) 225.

[3] TANiguCHI, S. - YAMAMOTO, M.: Sci. Rept. Res. Inst. Tohoku Univ. A6, (1954) 330.

[4] LUBORSKY, F. E. - WALTER, J. L.: IEEE Trans. Magn. 13 (1977) 953.

[5] ŠKORVÁNEK, I. - MARCIN, J. - KRENICKÝ, T. - KOVÁČ, J. - ŠVEC, P. - JANIČKOVIČ, D.: J.
Magn. Mang. Mater. 304 (2006) 203.

[6] HAGA, K.: Trans. J.I.M. 9 (1968) 88.

[7] YOSHIZAWA, Y. - YAMAUCHI, K.: IEEE Trans. Magn. 25, (1989) 3324.

[8] ŠKORVÁNEK, I. - MARCIN, J. - TURČANOVÁ, J. - WOJCIK, M. - NESTERUK, K. JANIČKOVIČ, D. - ŠVEC, P.: J. Magn. Magn. Mater. 310 (2007) 2494.

[9] OHODNICKI, JR. P. R. - QIN, Y. L. - McHENRY, M. E. - LAUGHLIN, D. E. - KEYLIN, V.: J. Magn. Magn. Mater. 322 (2010) 315.

[10] WILLARD, M. A. - LAUGHLIN, D. E. McHENRY, M. E. - THOMA, D. - SICKAFUS, K. - CROSS, J. O. - HARIS, V. G.: J.Appl. Phys. 84 (1998) 6773.

[11] McHENRY, M. E. - WILLARD, M. A. LAUGHLIN, D. E.: Progr. Mat. Sci. 44 (1999) 291.

[12] ŠKORVÁNEK, I. - ŠVEC, P. - MARCIN, J. KOVÁC̆, J. - KRENICKÝ, T. - DEANKO, M.: Phys. Stat. Sol. (a) 196, (2003) 217.

[13] JOHNSON, F. - GARMESTANI, H. - CHU, S. Y. McHENRY, M. E. - LAUGHLIN, D. E.: IEEE Trans. Magn. 40, (2004) 2697.

[14] SUZUKI, K. - ITO, N. - GARITAONANDIA, J. S. - CASHION, J.D.: J. Appl. Phys. 99 (2006) 08F114.

[15] MARCIN, J. - KLINDA, A. - SVEC, P. PRASLICKA, D. - BLAZEK, J. - KOVAC, J. SVEC, SR. P. - ŠKORVÁNEK, I.: IEEE Trans. Magn., 46 (2), (2010) 416.

[16] KOVÁČ, F. - STOYKA, V. - PETRYSHYNETS, I.: J. Magn. Magn. Mater. 320, (2008) 627.

[17] STOYKA, V. - KOVÁČ, F. - STUPAKOV, O. PETRYSHYNETS, I.: Mat. Charact. 61(2010) 1066.

Received November 30, 2012, accepted February 9, 2013

\section{BIOGRAPHY}

Jozef Kováč was born in 1954. In 1977 he graduated from the Faculty of Science, P. J. Šafárik University in Košice. He defended his CSc in 1989. Since 1977 he has been working at Institute of Experimental Physics Slovak Academy of Sciences, now as senior researcher in the Laboratory of Nanomaterials and Applied Magnetism. His research area is the study of magnetic properties of amorphous and nanocrystalline materials and nanoparticles. 